\title{
Non-invasive phenotyping using exhaled volatile organic compounds in asthma
}

\author{
Baharudin Ibrahim, ${ }^{1,2}$ Maria Basanta, ${ }^{1,2}$ Paul Cadden, ${ }^{1,2}$ Dave Singh, ${ }^{1,2}$ David Douce, ${ }^{3}$ \\ Ashley Woodcock, ${ }^{1,2}$ Stephen J Fowler ${ }^{1,2,4}$
}

\begin{abstract}
- Additional materials are published online only. To view these files please visit the journal online (http://thorax.bmj. com).

${ }^{1}$ Respiratory Research Group, Faculty of Medical and Human Sciences, University of Manchester, Manchester Academic Health Science Centre, Manchester, UK ${ }^{2}$ NIHR Translational Research Facility in Respiratory Medicine, University Hospital of South Manchester, Manchester, UK ${ }^{3}$ Waters Corporation, Manchester, UK

${ }^{4}$ Lancashire Teaching Hospitals NHS Foundation Trust, Preston, UK
\end{abstract}

\section{Correspondence to}

Stephen J Fowler, Lecturer and Honorary Consultant in Respiratory Medicine, University of Manchester and Lancashire Teaching Hospitals NHS Foundation Trust, Respiratory Research Group, Education and Research Centre, Wythenshawe Hospital, Southmoor Road Manchester M23 9LT, UK stephen.fowler@manchester. ac.uk

Received 7 December 2010 Accepted 27 May 2011 Published Online First 11 July 2011

\section{ABSTRACT}

Background Breath volatile organic compounds (VOCs) may be useful for asthma diagnosis and phenotyping, identifying patients who could benefit from personalised therapeutic strategies. The authors aimed to identify specific patterns of breath VOCs in patients with asthma and in clinically relevant disease phenotypes.

Methods Breath samples were analysed by gas chromatography-mass spectrometry. The Asthma Control Questionnaire was completed, together with lung function and induced sputum cell counts. Breath data were reduced to principal components, and these principal components were used in multiple logistic regression to identify discriminatory models for diagnosis, sputum inflammatory cell profile and asthma control.

Results The authors recruited 35 patients with asthma and 23 matched controls. A model derived from 15 VOCs classified patients with asthma with an accuracy of $86 \%$, and positive and negative predictive values of 0.85 and 0.89 , respectively. Models also classified patients with asthma based on the following phenotypes: sputum (obtained in 18 patients with asthma) eosinophilia $\geq 2 \%$ area under the receiver operating characteristics (AUROC) curve 0.98, neutrophilia $\geq 40 \%$ AUROC 0.90 and uncontrolled asthma (Asthma Control Questionnaire 21) AUROC 0.96 .

Conclusions Detection of characteristic breath VOC profiles could classify patients with asthma versus controls, and clinically relevant disease phenotypes based on sputum inflammatory profile and asthma control. Prospective validation of these models may lead to clinical application of non-invasive breath profiling in asthma.

\section{INTRODUCTION}

Current guideline-based treatment for asthma dictates stepwise increases in medication based on the concepts of disease control that are defined by symptoms and lung function. ${ }^{1}{ }^{2}$ A personalised approach to treatment targeted at individual disease characteristics may well improve outcomes but is as yet impractical in the clinic. Sputum cell counts can predict response to inhaled steroids and importantly indicate when increasing the dose of these potentially harmful therapies may be of no benefit. ${ }^{3}$ They also have the potential to direct novel and expensive therapies to specific patient groups, where a benefit in unselected patients with asthma has not been shown. ${ }^{4} 5$ Unfortunately, sputum induction and processing is time consuming, unpleasant for the patient and requires

\section{Key messages}

What is the key question?

- Could volatile organic compounds (VOCs) in the exhaled breath be useful as biomarkers for asthma?

What is the bottom line?

- Distinct patterns of VOCs differentiated the breath of patients with asthma from healthy controls and identified clinically relevant disease phenotypes such as sputum eosinophilia.

\section{Why read on?}

- Exhaled VOCs have potential for use as noninvasive biomarkers for asthma and lead to novel pathophysiological insights.

significant technical expertise. Caution is warranted in those with unstable or severe asthma, and adequate samples cannot be obtained in at least $10 \%$ of attempts even in the most experienced centres. $^{6}$

The detection of exhaled volatile organic compounds (VOCs) in the breath offers the opportunity for the discovery of novel diseasespecific biomarkers. Patterns of VOCs, as detected by an electronic nose, can distinguish patients with chronic obstructive pulmonary disease from those with asthma. ${ }^{7}$ Profiling VOCs by gas chromatography-mass spectrometry has also shown potential as a diagnostic tool for asthma in children. ${ }^{8}$ Exhaled VOCs may also be able to discriminate breath samples by the dominant inflammatory cell type. Cultured white cells both release and use VOCs, ${ }^{9}{ }^{10}$ and it is likely that the predominant airway inflammatory cell type will be associated with specific VOC profiles. Non-invasive assessment of metabolites in the breath therefore offers the potential for the discovery of novel biomarkers and for providing insights into inflammatory pathways.

The aim of the study was to investigate the discriminatory power of breath VOC profiles for differentiating the breath of patients with asthma from healthy controls and for classifying patients with asthma based on their sputum inflammatory cell profile and degree of disease control. This was a hypothesis-generating study, a valid and useful approach in metabolomics studies where there are few available data to inform a priori assumptions regarding which VOC patterns may or may not be relevant to the comparisons of interest. ${ }^{11}$ 


\section{METHODS}

Subjects

Volunteers were recruited from the research database of the Medicines Evaluation Unit, Wythenshawe Hospital. Inclusion and exclusion criteria are given in the online data supplement. Written informed consent was obtained, and the local ethics committee approved the study.

\section{Study design}

All subjects were asked to refrain from eating and drinking (except for unflavoured water) for $2 \mathrm{~h}$ prior to breath collection and from using their inhaled medication on the morning of the visit. A medical history and physical examination were performed before (in order): Asthma Control Questionnaire (ACO) ${ }^{12}$ exhaled breath collection, exhaled nitric oxide (eNO) measurement, spirometry and sputum induction with hypertonic saline.

\section{Measurements}

All breath samples were collected in the same room, used solely for this study, in an attempt to minimise the effect of variation in background air. Exhaled breath samples were collected using a breath sampler modified from that previously described. ${ }^{13}$ Subjects breathed VOC-filtered air (filter AX:456-06-20, 3M, Bracknell, UK) via a ResMed Mirage full-face mask of appropriate size (ResMed, Abingdon, UK). The air supply was generated by a continuous positive airway pressure device (Sullivan V, ResMed); a constant airflow through the system is necessary in order to minimise the effect of water vapour on the VOC profile. Respiratory pattern was tracked via a pressure transducer and visualised using bespoke software, enabling targeted sampling of breath from the lower respiratory tract, minimising contamination from the mouth, nose and upper airways as far as practicable. In short, the system tracked pressure changes at the mask, and the sampling software triggered sampling after a short prespecified delay following the pressure change from "baseline" (background mask pressure during inhalation) to "positive" (exhalation). Sampling stopped upon the signal returning to baseline, indicating the start of the next inhalation.

Subjects wore the mask for 5 min prior to sampling to acclimatise and to allow a degree of equilibration with the filtered air. For each breath sample, 3 litres of expiratory air was drawn across the absorbent bed via an Escort ELF laminar flow sampling pump (Kiesen Products, Chelmsford, UK), usually taking 5-7 min. Samples were collected in adsorbent tubes packed with Tenax TA/Carbotrap (Markes International, Llantrisant, UK), conditioned prior to sampling with pure $\mathrm{N}_{2}$ at $300^{\circ} \mathrm{C}$ and then at $320^{\circ} \mathrm{C}$ for $1 \mathrm{~h}$, respectively. Samples were analysed within a maximum of 5 days (stored at $4^{\circ} \mathrm{C}$ ) by gas chromatography-mass spectrometry (see online data supplement for details).

Exhaled nitric oxide was measured at $50 \mathrm{ml} / \mathrm{s}$ flow rate (Niox, Aerocrine, Sweden) with subjects exhaling slowly into the meter. The mean of three readings was taken as per ATS/ERS guidelines. ${ }^{14}$ Spirometry was performed using dry wedge spirometer (Vitalograph, Buckinghamshire, UK) according to standard guidelines. ${ }^{15}$ Finally, sputum induction was performed in accordance with European Respiratory Society recommendations. ${ }^{16}$ Further details are given in the online data supplement.

\section{Statistical analysis}

The aims of the study were to investigate whether the exhaled VOC profile could discriminate breath samples of (1) patients with asthma from healthy subjects, (2) patients with asthma having eosinophilic sputum from those having non-eosinophilic sputum and (3) patients with asthma having neutrophilic sputum from those having non-neutrophilic sputum. Cut-offs for sputum eosinophilia and neutrophilia of $2 \%$ and $40 \%$ were used. ${ }^{17}$ We also explored, as a secondary end point, whether the technique could classify patients with asthma on the basis of 'asthma control', defined by a score of $<1$ on the ACQ. ${ }^{12}{ }^{18}$ Full details of the statistical methodology are given in the online data supplement. In brief, for each comparison of interest, logistic regression was performed for each VOC and only discriminatory VOCs with $p<0.10$ were retained for inclusion in the subsequent modelling. Principal component analysis (PCA) was then used to reduce the dimensionality of the data, and these principal components (PCs) were included in multivariate logistic regression, in order to develop a classification model. The validity of the model was checked using discriminant function analysis in parallel with leave-one-out cross-validation.

\section{RESULTS}

Thirty-five patients with asthma and 23 healthy controls were recruited. Only one of the subjects had ever smoked: a patient with asthma having quit 5 years previously with a 2.5 pack year history. Ten of the patients with asthma had one or more comorbidities requiring regular medication: gastro-oesophageal reflux $(n=3)$, anxiety/depression (3), hypertension (4), hypothyroidism (1) and type II diabetes mellitus (1). Demographic details are shown in table 1.

\section{Asthma versus healthy controls}

Forty-seven exhaled VOCs classifying patients with asthma versus healthy subjects with $\mathrm{p}<0.10$ were used in the PCA to generate $12 \mathrm{PCs}$ explaining $82 \%$ of the variance. Stepwise logistic regression using these PCs as variables generated a predictive model of four PCs, which was able to classify patients with asthma with an accuracy of $86 \%$. Discriminant analysis confirmed the classification power of the model, with leave-one-out cross-validation accuracy of $83 \%$. The positive predictive and negative predictive values of the model were 0.85

Table 1 Demographic details of subjects included in the study

\begin{tabular}{|c|c|c|}
\hline & Asthma (n=35) & Healthy $(n=23$ \\
\hline Age & $46.1(14.4)$ & $50.8(14.0)$ \\
\hline Gender (M/F) & $17 / 18$ & $10 / 13$ \\
\hline BMl, $\mathrm{kg} / \mathrm{m}^{2}$ & $28.6(4.9)$ & $26.2(3.4)$ \\
\hline$\%$ predicted $\mathrm{FEV}_{1}$ & $91.5(22.1)^{*}$ & $109.8(17.7)$ \\
\hline$\%$ predicted FVC & $106.0(14.4)$ & $112.6(16.2)$ \\
\hline $\mathrm{FEV}_{1} / \mathrm{FVC}$ & $0.71(0.11)^{*}$ & $0.79(0.06)$ \\
\hline Exhaled nitric oxide, ppb & $29.2(22.6)$ & NA \\
\hline \multicolumn{3}{|l|}{ Treatment $(\mathrm{n})$} \\
\hline As required, bronchodilators only & 10 & NA \\
\hline ICS only & 11 & NA \\
\hline Combination inhalers & 14 & NA \\
\hline $\begin{array}{l}\text { Daily inhaled steroid dose, mcg } \\
\text { (beclomethasone dose equivalent) }\end{array}$ & $568.6(756.1)$ & NA \\
\hline \multicolumn{3}{|l|}{ Sputum cell profile $†$} \\
\hline$\geq 2 \%$ eos, $\geq 40 \%$ neuts & $22.2 \%$ & NA \\
\hline$\geq 2 \%$ eos, $<40 \%$ neuts & $22.2 \%$ & NA \\
\hline$<2 \%$ eos, $\geq 40 \%$ neuts & $33.3 \%$ & NA \\
\hline$<2 \%$ eos, $<40 \%$ neuts & $22.2 \%$ & NA \\
\hline
\end{tabular}

Data shown as mean (SD) except where indicated.

${ }^{*} \mathrm{p}<0.05$ versus healthy controls.

$\dagger \mathrm{n}=18$.

eos, eosinophils; FEV ${ }_{1}$, forced expiratory volume in one second; FVC, forced vital capacity; ICS, inhaled corticosteroids; neuts, neutrophils. 
and 0.89 , respectively. Plots of the contributing compounds for each $\mathrm{PC}$ are shown in figure 1.

\section{Asthma phenotypes}

Eighteen subjects with asthma were able to provide induced sputum samples for cell counting. There were no significant demographic differences between those who could and could not produce an adequate sputum sample, for example, in terms of age, lung function, ACQ score, inhaled steroid use or dose. Those with sputum eosinophils $\geq 2 \%(n=8)$ had lower forced expiratory volume in one second $\left(\mathrm{FEV}_{1}\right)$ and forced vital capacity compared with the non-eosinophilic group (table 2). Eleven discriminating compounds were used in the PCA, reduced to four PCs explaining 85\% of the variance. Logistic regression produced a model using three of these PCs with a classification accuracy of $83 \%$. Discriminant function analysis had a leaveone-out cross-validation accuracy of $83 \%$, and the area under the receiver operating characteristic (AUROC) for the model was 0.98 (other ROC parameters are shown in table 3). For comparison, a high exhaled NO (cut-off based on ${ }^{19}$ ) was able to predict sputum eosinophilia in our cohort with an AUROC curve of 0.69 (data not shown). Model parameters and contributing compounds are shown in table 4 and the ROC curve in figure 2.

The eight subjects with a sputum neutrophil count $\geq 40 \%$ were older than those without (table 2). Univariate analysis identified 14 discriminating compounds, reduced to five PCs by PCA explaining $81 \%$ of the variance. Logistic regression generated a model comprising one PC with an accuracy of $79 \%$, discriminant function leave-one-out cross-validation accuracy $72 \%$ and AUROC curve of 0.90 (tables 3 and 4, figure 2).

Eighteen subjects had uncontrolled asthma ( $\mathrm{ACQ} \geq 1$ ); they had poorer lung function and were on higher levels of treatment compared with the 17 controlled subjects (table 2). Thirteen discriminating compounds produced five PCs in PCA explaining $65 \%$ of the variance. The logistic regression model included four of these PCs and had an accuracy of $89 \%$. Discriminant function analysis had a leave-one-out cross-validation accuracy of $80 \%$ and the AUROC curve was 0.97 (tables 3 and 4, figure 2).

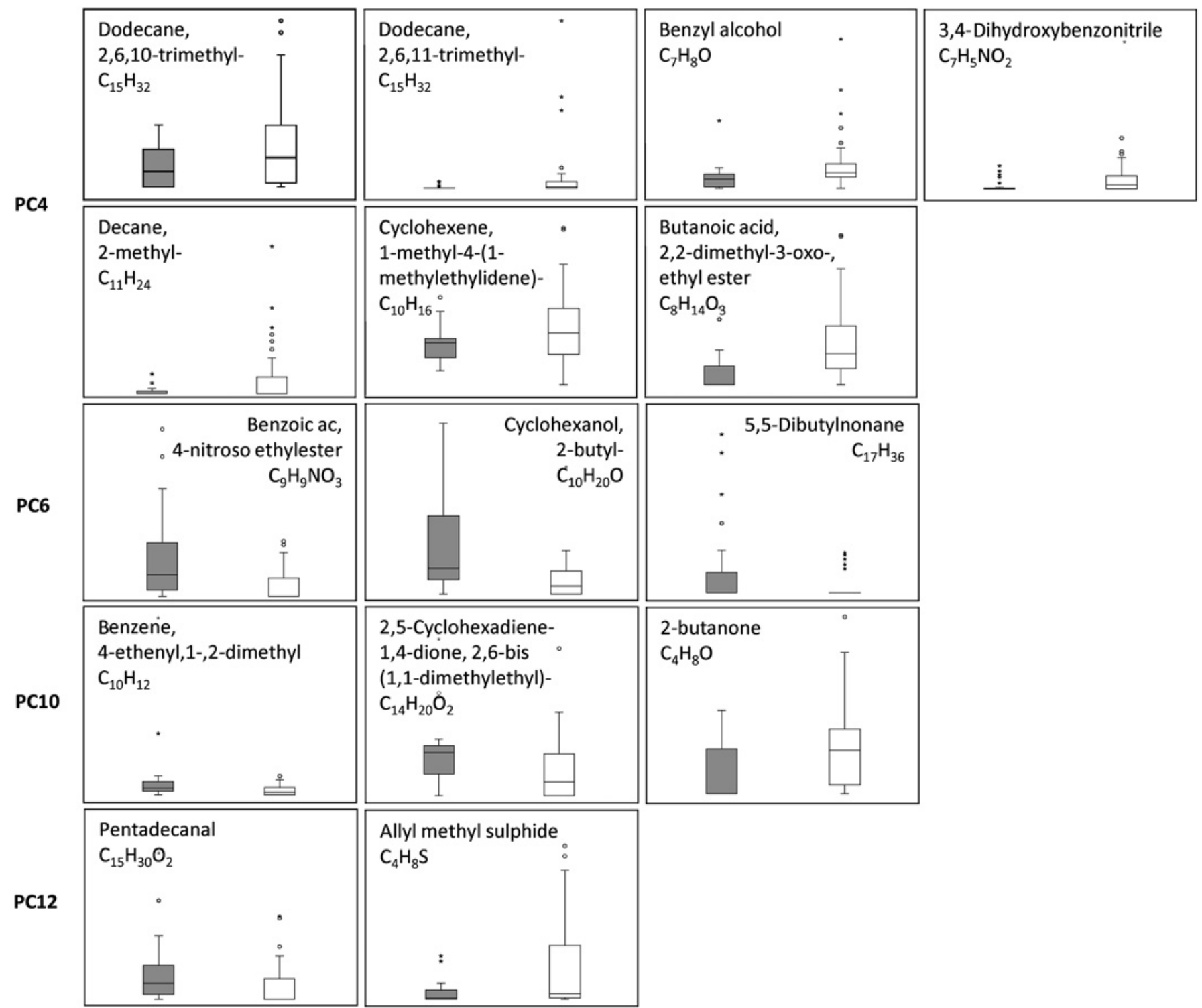

Figure 1 Box-and-whisker plots of relative intensity for the individual discriminating volatile organic compounds used for each principal component in the model predicting healthy controls (grey boxes) versus patients with asthma (white boxes). 
Table 2 Demographics for subgroup comparisons

\begin{tabular}{|c|c|c|c|c|c|c|}
\hline & \multicolumn{2}{|c|}{ Sputum eosinophils } & \multicolumn{2}{|c|}{ Sputum neutrophils } & \multicolumn{2}{|c|}{ Asthma Control Questionnaire } \\
\hline & $\geq 2 \%(n=8)$ & $<2 \%(n=10)$ & $\geq 40 \%(n=10)$ & $<40 \%(n=8)$ & $<1(n=17)$ & $\geq 1(n=18)$ \\
\hline Age, mean (SD) & $46.8(15.1)$ & $47.5(10.7)$ & $52.7(10.8)$ & $40.3(11.3)^{*}$ & $42.9(16.0)$ & $49.1(12.5)$ \\
\hline Gender (M/F) & $5 / 3$ & $5 / 5$ & $6 / 4$ & $4 / 4$ & $8 / 9$ & $9 / 9$ \\
\hline Predicted FVC (\%), mean (SD) & $98.9(8.0)$ & $113.2(13.7)^{*}$ & $106.5(14.5)$ & $107.3(12.9)$ & $111.9(14.5)$ & $100.5(12.2)^{*}$ \\
\hline $\mathrm{FEV}_{1} / \mathrm{FVC}$ & $62.4(13.4)$ & $74.5(6.7)^{*}$ & $65.8(13.0)$ & $73.2(8.8)$ & $77.7(6.5)$ & $65.1(11.4)^{*}$ \\
\hline Inhaled steroids $(\mathrm{Y} / \mathrm{N})$ & $8 / 0$ & $7 / 3$ & $9 / 1$ & $6 / 2$ & $7 / 10$ & $18 / 0^{*}$ \\
\hline
\end{tabular}

${ }^{*} p \leq 0.05$ versus comparator group.

$\mathrm{FEV}_{1}$, forced expiratory volume in one second; FVC, forced vital capacity.

\section{DISCUSSION}

We have demonstrated that breath VOC analysis can discriminate patients with asthma from healthy controls and also identify clinically important disease phenotypes related to sputum inflammation and a measure of asthma control. While these findings need to be validated in an independent cohort of patients, we have provided a degree of internal validation using discriminant function analysis. Furthermore, our analysis has identified a number of potential new biomarkers for asthma and its phenotypes.

Several of the compounds that were raised in patients with asthma compared with controls were alkanes. Alkanes arise as products of lipid peroxidation, ${ }^{20}$ and raised levels of exhaled pentane have previously been demonstrated in acute asthma. ${ }^{21}$ However, pentane appears to be relatively non-specific as levels are also raised in other inflammatory conditions such as rheumatoid arthritis ${ }^{22}$ and inflammatory bowel disease. ${ }^{23}$ The alkanes found to be discriminatory in our study and others (such as 2,6,11-trimethyl-dodecane ${ }^{24}$ ) are longer chain alkanes, which may be more specific to asthma. Two unidentified compounds also likely to be alkanes or methylated alkanes (both $\mathrm{C}_{13} \mathrm{H}_{28}$ ) were also found to be raised in children with asthma. ${ }^{8}$ With differing selection criteria, breath collection and analytical methodologies, it is unsurprising that we have not identified an identical list of discriminating VOCs to previous asthma studies, $^{8} 24$ although the repeated discovery of similar compounds (alkanes and methylated alkanes) under differing experimental conditions adds strength to the evidence that these may well be important. Methylated alkanes have been shown to increase with age and probably further relate to oxidative stress. ${ }^{25}$ Another potential source of oxidative stress may result from conditions coexistent with asthma, such as obesity and hypertriglyceridaemia, ${ }^{26}$ although in our cohort the mean BMI of the healthy and asthmatic groups was similar. We would propose that this group of compounds $\left(C_{7}\right.$ to $C_{12}$ alkanes and their methylated derivatives) merits further exploration as a potential biomarker for asthma.
Our models were able to predict both neutrophilic and eosinophilic sputum cell phenotypes with very high diagnostic accuracy. Furthermore, the intensity of many of the compounds contributing to the models (and the overall models themselves) correlated with the percentage of cells of interest, strengthening the association. There were no clear patterns in terms of classes of compounds seen in this part of the analysis, but should these be confirmed in an independent cohort, then investigation into the relevance and origin of the discriminatory compounds would be indicated. Despite the evidence that sputum analysis can be used to personalise asthma treatment, ${ }^{3627}$ it has not been adopted into routine management outside specialist asthma units for several reasons: sputum induction, processing and interpretation are time consuming and require experienced and skilled personnel; samples cannot be obtained in a significant minority of subjects; samples must be analysed within a few hours of collection and care must be taken in those with uncontrolled or severe disease. By contrast, breath analysis offers the opportunity for surrogates to be detected in a non-invasive, straightforward way. Future developments may also lead to online detection as has been achieved with eNO. In fact, we found that the exhaled breath VOC profile predicted sputum eosinophilia more accurately than eNO in our cohort. Although ours was a small sample, similar results have recently been reported for predicting sputum eosinophilia $\geq 3 \%$ using eNO with an AUROC of 0.78 . $^{28}$ eNO may in fact provide complementary information to exhaled VOCs and a combined model may be even more powerful. It should be noted that just over half of our participants were able to provide sputum for analysis and thus may not be entirely representative of the group as a whole, although demographic data were not different between sputum producers and nonproducers (data not shown). It is unclear why we were only able to obtain viable sputum samples in just over half of these subjects, although one could speculate that the airway-drying effect of unhumidified continuous positive airway pressure may have had an impact on subsequent successful sputum induction. We will investigate this possibility in future studies.

Table 3 Receiver operating characteristics of the multivariate models for the asthma phenotypes of interest

\begin{tabular}{llll}
\hline & $\begin{array}{l}\text { Eosinophilic versus } \\
\text { non-eosinophilic }\end{array}$ & $\begin{array}{l}\text { Neutrophilic versus } \\
\text { non-neutrophilic }\end{array}$ & $\begin{array}{l}\text { Controlled versus } \\
\text { not controlled }\end{array}$ \\
\hline Sensitivity & 0.75 & 0.80 & 0.89 \\
Specificity & 0.90 & 0.75 & 0.88 \\
Positive predictive value & 0.86 & 0.80 & 0.89 \\
Negative predictive value & 0.82 & 0.75 & 0.88 \\
AUROC (95\% Cl) & $0.98(0.91$ to 1.00$)$ & $0.90(0.76$ to 1.00$)$ & $0.97(0.93$ to 1.00$)$ \\
Cross-validation accuracy & $83 \%$ & $72 \%$ & $80 \%$ \\
\hline
\end{tabular}

Leave-one-out cross-validation accuracy from discriminant function analysis also shown.

AUROC, area under the receiver operating characteristic. 
Table 4 Model parameters and compounds for subgroup comparisons

\begin{tabular}{|c|c|c|c|c|}
\hline & \multicolumn{2}{|c|}{ Logistic regression model } & \multirow[b]{2}{*}{ Compound ID } & \multirow[b]{2}{*}{$\mathbf{r}$} \\
\hline & PCs & Exp B (95\% CI) & & \\
\hline \multirow[t]{6}{*}{ Eosinophils $\geq 2 \%$} & \multirow[t]{2}{*}{ PC2 } & \multirow[t]{2}{*}{$40.12(0.03$ to 51227.97$)$} & ${ }^{*}$ Camphene $\mathrm{C}_{10} \mathrm{H}_{16}$ & -0.47 \\
\hline & & & 1,1-Dimethylpropyl 2-ethylhexanoate $\mathrm{C}_{13} \mathrm{H}_{26} \mathrm{O}_{2}$ & -0.40 \\
\hline & \multirow[t]{2}{*}{ PC3 } & \multirow[t]{2}{*}{$0.13(0.01$ to 1.62$)$} & ${ }^{*}$ (7a-Isopropenyl-4,5-dimethyloctahydroinden-4-yl) methanol $\mathrm{C}_{15} \mathrm{H}_{26} \mathrm{O}$ & -0.58 \\
\hline & & & Cyclohexanone $\mathrm{C}_{6} \mathrm{H}_{10} \mathrm{O}$ & -0.46 \\
\hline & PC4 & $0.03(0.00$ to 7.98$)$ & ${ }^{*}$ Bicyclo[4.1.0] hept-2-ene, 3,7,7-trimethyl $\mathrm{C}_{10} \mathrm{H}_{16}$ & -0.60 \\
\hline & \multicolumn{2}{|c|}{ Overall model ${ }^{*}$} & & 0.71 \\
\hline \multirow[t]{5}{*}{ Neutrophils $\geq 40 \%$} & \multirow[t]{5}{*}{$\mathrm{PC1}$} & \multirow[t]{5}{*}{$32.90(1.27$ to 849.96$)$} & ${ }^{*}$ Cyclopentene, 1,3-dimethyl-2-(1-methylethyl) $\mathrm{C}_{10} \mathrm{H}_{18}$ & 0.54 \\
\hline & & & ${ }^{*}$ Naphthalene, 2,7-dimethyl $\mathrm{C}_{12} \mathrm{H}_{12}$ & 0.53 \\
\hline & & & Cyclohexanol, 3,5-dimethyl $\mathrm{C}_{8} \mathrm{H}_{16} \mathrm{O}$ & 0.44 \\
\hline & & & Tetradecane, 4-methyl $\mathrm{C}_{15} \mathrm{H}_{32}$ & 0.42 \\
\hline & & & Decahydro-8a-ethyl-1,1,4a,6-tetramethylnaphthalene $\mathrm{C}_{16} \mathrm{H}_{30}$ & 0.40 \\
\hline \multirow{7}{*}{ ACQ score $\geq 1$} & \multirow{2}{*}{ PC3 } & \multirow{2}{*}{$0.15(0.03$ to 0.76$)$} & ${ }^{*}$ Bicyclo[3.1.0]hex-2-ene, 4-methylene-1-(1-methylethyl) $\mathrm{C}_{10} \mathrm{H}_{14}$ & 0.42 \\
\hline & & & ${ }^{*} 0$-xylene $\mathrm{C}_{8} \mathrm{H}_{10}$ & 0.42 \\
\hline & \multirow[t]{2}{*}{ PC4 } & \multirow[t]{2}{*}{$0.18(0.03$ to 1.01$)$} & *2-Butanone, 3-methyl/butanal, 2-methyl $\mathrm{C}_{5} \mathrm{H}_{10} \mathrm{O}$ & -0.36 \\
\hline & & & ${ }^{*} 2,2,4,4$-Tetramethyloctane $\mathrm{C}_{12} \mathrm{H}_{26}$ & -0.34 \\
\hline & \multirow[t]{2}{*}{ PC5 } & \multirow[t]{2}{*}{$0.09(0.01$ to 0.99$)$} & ${ }^{*}(1 \mathrm{E})$-1-(methylsulphanyl)1-propene $\mathrm{C}_{4} \mathrm{H}_{8} \mathrm{~S}$ & -0.44 \\
\hline & & & 2,6-diisopropylnaphtalene $\mathrm{C}_{16} \mathrm{H}_{20}$ & -0.17 \\
\hline & \multicolumn{2}{|c|}{ Overall model* } & & 0.77 \\
\hline
\end{tabular}

Asterisk indicates a significant correlation $(\mathrm{p} \leq 0.05)$ between the compound or overall model and the variable of interest (eg, camphene is inversely correlated with sputum eosinophil count, $r=-0.47, p \leq 0.05)$.

ACQ, Asthma Control Questionnaire; PCs, principal components.

Excellent diagnostic accuracy was also demonstrated identifying patients with asthma with poor disease control. Asthma control is a measure of symptoms related to current disease activity and, to a degree, is independent of disease severity. As such, recent guidelines have emphasised the importance of achieving disease control. ${ }^{1}$ The seven-item ACO includes six items relating to symptoms and reliever use over the previous week, and one item for $\mathrm{FEV}_{1}$. It is likely therefore that our results were confounded by $\mathrm{FEV}_{1}$ (lower in those with worse

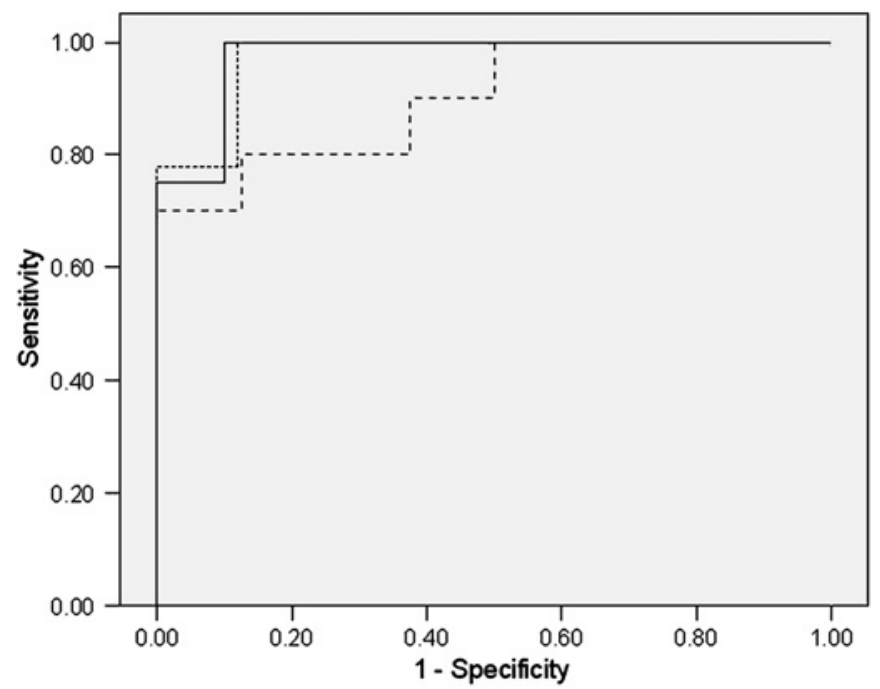

Figure 2 Receiver operating characteristic curves for the models predicting eosinophilic versus non-eosinophilic asthma (solid line); neutrophilic versus non-neutrophilic asthma (dashed line) and controlled versus uncontrolled asthma (dotted line). disease control) and treatment (more taken by those with poor control). The factors underlying poor control are complex and are related to inflammatory, physiological and psychological status. All these factors could affect the levels of VOCs in the breath, and teasing out relationships between specific VOCs and asthma control will require very large prospective cohort studies.

There was overlap between the group with poor asthma control and the eosinophilic subtype, with all but one of the eosinophilic subjects having poor asthma control, and so in this study it is perhaps more accurate to say that the 'eosinophilic' VOC profile identified above in fact represents a group with persistent eosinophilia and poor asthma control despite the use of inhaled steroids. The discriminating compounds for the asthma control comparison were different to those that identified eosinophilia. The origins of poor asthma control are multifactorial, with sputum eosinophilia being only one of those factors. The majority (10 out of 18) of the poorly controlled subjects were unable to produce sputum for analysis, and it may be that other more dominant factors were associated with the level of control in the remainder and thus had a significant influence on the VOC profile of this group.

Another source of exhaled VOCs may be the home environment. Several have been found in raised concentration in the homes of patients with asthma compared with controls. For example, we found o-xylene to be raised in subjects, and moderately correlated, with poor asthma control. This has previously been detected in environmental studies, where raised levels in ambient air samples have been associated with increased symptoms in children with asthma. ${ }^{29}{ }^{30}$ The risk of asthma is also increased by residing in industrial and urban areas, where environmental concentrations of alkanes are high. ${ }^{31}$ Thus home environment may be having a confounding effect on the discriminating VOCs that we have found in the breath. Exhaled 
breath VOCs include those from alveolar air, reflecting systemic exposure. The kinetics of inhaled VOCs are therefore not dependent simply on equilibration between lung air and atmospheric air, but will behave according to concepts familiar from basic pharmacokinetics, that is, adsorption, distribution, metabolism and excretion. ${ }^{32}$ These same principles also inform our practice in dealing with the potential effect of environmental VOCs within the sampling room. One approach is to sample the environment at the time of breath sampling and subtract this background from the breath profile. ${ }^{33}$ This assumes equilibrium exists between the breath and the environment at all times, which is not likely to be the case where subjects will have moved through several environments in the hours and days prior to sampling. We have attempted to control this potential problem as far as reasonable by using a VOC filter in our sampling circuit and sampling in the same room (used exclusively for this purpose) throughout the study. Furthermore, we would expect any influence of the background signal to be balanced between the cases and the controls with this study design, as long as subjects were not sampled in group-related sequence (eg, cases first, controls second) over the course of the study.

It is important to recognise the characteristics of the subjects with asthma who were included in this study. These were patients with a doctor's diagnosis of asthma, with current symptoms of the disease and requiring at least one asthma medication. We felt it important to address 'real world' subjects with asthma rather than those strictly defined by objective tests such as bronchodilator reversibility, which are often negative in patients treated with regular inhaled steroids. Nevertheless, many of our subjects did have some objective evidence of asthma as recommended in the most recent British Thoracic Society guidelines ${ }^{2}: 71 \%$ had at least one of bronchodilator reversibility ( $\geq 400 \mathrm{ml}$ ), bronchial hyper-responsiveness (methacholine $\mathrm{PC}_{20} \leq 8 \mathrm{mg} / \mathrm{ml}$ ), sputum eosinophilia ( $\geq 2 \%$ ) or raised exhaled $\mathrm{NO}$ ( $\geq 25 \mathrm{ppb}$ at $50 \mathrm{ml} / \mathrm{sec}$ ). Of the remainder, all but two had some suggestive but less definite evidence (atopy, requirement for prednisolone treatment in the previous year, borderline eosinophilia ( $\geq 1 \%$ ) or reversibility ( $\geq 200 \mathrm{ml})$ ).

In conclusion, we have shown that breath VOCs can be used to discriminate patients with asthma from healthy controls as well as important disease phenotypes related to airway inflammation and disease control. Further prospective studies are now required to validate these models and should include patients where the diagnosis is as yet unknown. Such validation will allow future work to be directed towards developing point-ofcare devices for breath phenotyping that can be used in clinical trials as well as in the outpatient clinic.

Acknowledgements Our thanks go to GlaxoSmithKline for contributing to the funding of this study and Waters Corporation for loan of mass spectrometry equipment. We also acknowledge Richard Knowles for his review of the manuscript and Julie Morris for statistical advice. BI gratefully acknowledges Universiti Sains Malaysia for funding.

Funding GlaxoSmithKline kindly contributed towards the funding of this study.

Competing interests None.

Ethics approval This study was conducted with the approval of the Tameside and Glossop REC (now known as North West 8 REC-Greater Manchester East).

Provenance and peer review Not commissioned; externally peer reviewed.

\section{REFERENCES}

1. Bateman ED, Hurd SS, Barnes PJ, et al. Global strategy for asthma management and prevention: GINA executive summary. Eur Respir J 2008;31:143-78.
2. British Thoracic Society Scottish Intercollegiate Guidelines Network. British Guideline on the Management of Asthma. Thorax 2008;63(Suppl 4):iv1-121.

3. Green RH, Brightling CE, Woltmann G, et al. Analysis of induced sputum in adults with asthma: identification of subgroup with isolated sputum neutrophilia and poor response to inhaled corticosteroids. Thorax 2002;57:875-9.

4. Nair P, Pizzichini MM, Kjarsgaard M, et al. Mepolizumab for prednisone-dependent asthma with sputum eosinophilia. N Engl J Med 2009;360:985-93.

5. Flood-Page P, Swenson C, Faiferman I, et al; International Mepolizumab Study Group. A study to evaluate safety and efficacy of mepolizumab in patients with moderate persistent asthma. Am J Respir Crit Care Med 2007;176:1062-71.

6. Green RH, Brightling CE, McKenna S, et al. Asthma exacerbations and sputum eosinophil counts: a randomised controlled trial. Lancet 2002;360:1715-21.

7. Fens N, Zwinderman AH, van der Schee MP, et al. Exhaled breath profiling enables discrimination of chronic obstructive pulmonary disease and asthma. Am J Respir Crit Care Med 2009;180:1076-82.

8. Dallinga JW, Robroeks CM, van Berkel JJ, et al. Volatile organic compounds in exhaled breath as a diagnostic tool for asthma in children. Clin Exp Allergy 2010:40:68-76.

9. Shin HW, Umber BJ, Meinardi S, et al. Acetaldehyde and hexanaldehyde from cultured white cells. J Trans/ Med 2009:7:31.

10. Shin HW, Umber BJ, Meinardi S, et al. Gas signatures from cultured human leukocytes. Am J Respir Crit Care Med 2010;181:A5740.

11. Kell DB, Oliver SG. Here is the evidence, now what is the hypothesis? The complementary roles of inductive and hypothesis-driven science in the post-genomic era. Bioessays 2004;26:99-105.

12. Juniper EF, O'Byrne PM, Guyatt GH, et al. Development and validation of a questionnaire to measure asthma control. Eur Respir J 1999;14:902-7.

13. Basanta M, Koimtzis T, Singh D, et al. An adaptive breath sampler for use with human subjects with an impaired respiratory function. Analyst 2007;132:153-63.

14. American Thoracic Society; European Respiratory Society. ATS/ERS recommendations for standardized procedures for the online and offline measurement of exhaled lower respiratory nitric oxide and nasal nitric oxide, 2005 Am J Respir Crit Care Med 2005;171:912-30.

15. Miller MR, Hankinson J, Brusasco V, et al; ATS/ERS Task Force. Standardisation of spirometry. Eur Respir J 2005;26:319-38.

16. Paggiaro PL, Chanez P, Holz 0, et al. Sputum induction. Eur Respir J Suppl 2002;37:3s-8s.

17. Hastie AT, Moore WC, Meyers DA, et al; National Heart, Lung, and Blood Institute Severe Asthma Research Program. Analyses of asthma severity phenotypes and inflammatory proteins in subjects stratified by sputum granulocytes. J Allergy Clin Immunol 2010;125:1028-36.e13.

18. Juniper EF, Bousquet J, Abetz L, et al. Identifying 'well-controlled' and 'not well-controlled' asthma using the Asthma Control Questionnaire. Respir Med 2006:100:616-21.

19. Taylor DR, Pijnenburg MW, Smith AD, et al. Exhaled nitric oxide measurements: clinical application and interpretation. Thorax 2006;61:817-27.

20. Kneepkens CM, Lepage G, Roy CC. The potential of the hydrocarbon breath test as a measure of lipid peroxidation. Free Radic Biol Med 1994;17:127-60.

21. Olopade CO, Zakkar M, Swedler WI, et al. Exhaled pentane levels in acute asthma. Chest 1997:111:862-5.

22. Humad S, Zarling E, Clapper M, et al. Breath pentane excretion as a marker of disease activity in rheumatoid arthritis. Free Radic Res Commun 1988;5:101-6.

23. Kokoszka J, Nelson RL, Swedler WI, et al. Determination of inflammatory bowel disease activity by breath pentane analysis. Dis Colon Rectum 1993;36:597-601.

24. Dragonieri S, Schot R, Mertens BJ, et al. An electronic nose in the discrimination of patients with asthma and controls. J Allergy Clin Immunol 2007;120:856-62.

25. Phillips M, Cataneo RN, Greenberg J, et al. Effect of age on the breath methylated alkane contour, a display of apparent new markers of oxidative stress. J Lab Clin Med 2000;136:243-9.

26. Cottrell L, Neal WA, Ice $\mathrm{C}$, et al. Metabolic abnormalities in children with asthma Am J Respir Crit Care Med 2011:183:441-8.

27. Petsky HL, Cates CJ, Lasserson TJ, et al. A systematic review and meta-analysis: tailoring asthma treatment on eosinophilic markers (exhaled nitric oxide or sputum eosinophils). Thorax. Published Online First: 11 October 2010. doi:10.1136/ thx.2010.135574.

28. Schleich FN, Seidel L, Sele J, et al. Exhaled nitric oxide thresholds associated with a sputum eosinophil count $\geq 3 \%$ in a cohort of unselected patients with asthma. Thorax 2010;65:1039-44.

29. Delfino RJ, Gong H, Linn WS, et al. Respiratory symptoms and peak expiratory flow in children with asthma in relation to volatile organic compounds in exhaled breath and ambient air. J Expo Anal Environ Epidemiol 2003;13:348-63.

30. Hulin M, Caillaud D, Annesi-Maesano I. Indoor air pollution and childhood asthma: variations between urban and rural areas. Indoor Air 2010;20:502-14.

31. Wichmann FA, Müller A, Busi LE, et al. Increased asthma and respiratory symptoms in children exposed to petrochemical pollution. J Allergy Clin Immuno 2009;123:632-8

32. Pleil JD, Kim D, Prah JD, et al. Exposure reconstruction for reducing uncertainty in risk assessment: example using MTBE biomarkers and a simple pharmacokinetic model. Biomarkers 2007;12:331-48.

33. Phillips $\mathbf{M}$, Herrera J, Krishnan S, et al. Variation in volatile organic compounds in the breath of normal humans. J Chromatogr B Biomed Sci Appl 1999;729:75-88. 